\title{
A Comparative Study of Orotracheal Intubation Guided by Airtraq and McCoy Laryngoscope in Patients with Rigid Cervical Collar In-situ Simulating Cervical Immobilization for Traumatic Cervical Spine Injury
}

\author{
Akhil Diwan $^{1}$ Shobha Purohit ${ }^{1}$
}

${ }^{1}$ Department of Anesthesia, SMS Hospital, Jaipur, Rajasthan, India

Address for correspondence Shobha Purohit, MD, Department of Anesthesia, SMS Hospital, Bangar Complex, First Floor, Jaipur 302004, Rajasthan, India (e-mail: purohit.shobha@gmail.com).

Indian J Neurosurg 2019;8:161-167

\begin{abstract}
Keywords

- Airtraq laryngoscope

- McCoy laryngoscope

- duration of intubation

- hemodynamic response

Background Immobilization of cervical spine is of utmost importance in patients with cervical injury, making intubation a difficult task due to the application of cervical collar. This study was done to assess which laryngoscope (Airtraq or McCoy) is better for intubation and prevents the deleterious effects of hypoxia by comparing the intubation time.

Methods A prospective interventional randomized study was undertaken in 60 adult patients of American Society of Anesthesiologists (ASA) grade I and II, aged between 20 and 50 years, scheduled for various surgical procedures requiring tracheal intubation for anesthesia. Patients were randomly allocated to undergo intubation with either the Airtraq (Group A; $n=30$ ) laryngoscope or McCoy (Group B; $n=30$ ). Patients were intubated following the standard anesthetic protocol, and the differences in duration of intubation, changes in the hemodynamic parameters in response to intubation, modified intubation difficulty score, and airway complications between the Airtraq and the McCoy laryngoscope were compared.

Results Overall intubation success rates were $100 \%$ with both devices and a similar number of intubation attempts were required. Though the mean time required for successful intubation was less with the Airtraq ( $25.2 \pm 5.11$ seconds) than the McCoy laryngoscope ( $27.3 \pm 4.47$ seconds); it was statistically insignificant $(p=0.14)$. Intubation difficulty score and ease of insertion were significantly less in Airtraq laryngoscope when compared with McCoy laryngoscope. Increase in the heart rate and mean arterial pressure was significantly more just after intubation with McCoy in comparison with Airtraq laryngoscope. However, the frequencies of airway complications were similar. Conclusion Intubation time despite being lesser with the Airtraq than the McCoy laryngoscope was statistically insignificant, and overall success rates between the two devices were similar.
\end{abstract}

\section{Introduction}

Cervical spine injury occurs in 1 to $4 \%$ of all major trauma victims. ${ }^{1}$ However, these injuries are often associated with significant morbidity and mortality, largely as a result of

received

April 27, 2019

accepted

July 29, 2019

published online

September 30, 2019 accompanying spinal cord injuries. ${ }^{2}$ Although very little can be done about the initial injury to the spinal cord, utmost care should be taken to prevent secondary insults, particularly with regard to appropriate spinal immobilization during airway management., ${ }^{2,3}$ During any airway intervention in

C2019 Neurological Surgeons'

License terms

Society of India 
such patients, maintenance of head in a midline neutral position is essential to avoid potentially catastrophic neurological sequelae. ${ }^{2,4}$

Direct laryngoscopy requires flexion of the cervical spine and atlanto-occipital extension, which helps in alignment of the oral, pharyngeal and laryngeal axes, thus creating a direct line of vision from the mouth to the vocal cords. However, this may be hazardous in cervical spine injury patient.

In patients with cervical spine immobility or instability, intubation requires two contradicting objectives: sufficient laryngeal exposure and least cervical movement.

To restrict the cervical spine movements in such case, a rigid cervical collar is applied, which reduces mouth opening, thus hindering tracheal intubation with the standard laryngoscope. ${ }^{5}$ Besides this, cervical collar lifts up the chin and moves the larynx anteriorly, further adding to the difficult intubation. ${ }^{6}$ The anterior portion of the collar can be removed to facilitate tracheal intubation. However, this jeopardizes the safety of cervical spine. Manual inline stabilization that is recommended for cervical spine immobilization also impairs the glottic visualization. ${ }^{7}$

Even with a cervical collar in situ, there are various airway devices such as lighted stylet, intubating laryngeal mask airway (LMA), and Macintosh laryngoscope which have been shown to augment the easy placement of endotracheal tube with minimal cervical movement., ${ }^{89}$ It has been suggested that fiber optic intubation is the most reliable method of intubation in patients with cervical injury. ${ }^{10}$ But it may not be widely available everywhere and its use requires good skill and practice.

Traditionally, McCoy laryngoscope is used when the cervical spine movement is not desired, as it provides better glottic view by elevating epiglottis with the movement of hinged tip. Airtraq is an optical laryngoscope that uses magnifying wide-angle mirrors, a light emitting diode light source, and a tracheal tube guide channel, to facilitate rapid visualization and passage of an endotracheal tube. First, it permits visualization of the glottis without alignment of the oral and pharyngeal axes and second allows intubation without hyperextension of neck. Both McCoy and Airtraq have shown to be effective in managing airway in difficult airway situations as well as in simulated patients with a cervical collar. ${ }^{11}$

The present study aimed to compare the orotracheal intubation guided by Airtraq and McCoy laryngoscope in the presence of rigid cervical collar simulating cervical spine immobilization in patients undergoing surgery.

\section{Materials and Methods}

This hospital based-randomized interventional study was conducted between February 2016 and November 2016, after approval from institutional ethics committee and research review board. A total of 60 adult patients of American Society of Anesthesiologist (ASA) physical status I and II of both genders aged 20 to 50 years, who were scheduled for elective surgery requiring general anesthesia and intubation were included in two groups (intubation guided by either Airtraq or McCoy laryngoscope) consisting of 30 patients each. The sample size was decided on the basis of 95\% confidence interval and $80 \%$ power to verify the expected difference of $10.03 \pm 14$ seconds in mean intubation time with Airtraq (28.73 seconds) and McCoy (39.11 seconds) laryngoscope. Written informed consent was taken from all the patients.

Exclusion criteria included patient's refusal to participate, anticipated difficult intubation (Mallampatti grade 4, thyromental distance $<6 \mathrm{~cm}$, sternomental distance $<12 \mathrm{~cm}$, mentohyoid distance $<5 \mathrm{~cm}$, and/or neck circumference $>42 \mathrm{~cm}$ ), patients with risk of pulmonary aspiration of gastric contents, pregnant patients, morbid obesity, history of cervical spine pathology, airway distortion or trauma.

Randomization was done by computer-generated random number table, and the random numbers were kept in sequentially numbered opaque envelopes. The envelope was opened and the patient was allocated to one of the two groups, according to the technique to be used for intubation. Patients included in group A $(n=30)$ were intubated with Airtraq laryngoscope while those in Group B $(n=30)$ were intubated with McCoy laryngoscope.

On arrival in the operation theater, fasting status, consent, and preanesthetic check-ups were checked. Rigid cervical collar was applied. Baseline parameters (heart rate [HR], systolic blood pressure [SBP], diastolic blood pressure [DBP], and mean arterial pressure [MAP]) were recorded. Two intravenous lines with $18 \mathrm{G}$ cannula were secured. Ringer lactate drip was started. Premedication with Inj. glycopyrrolate (0.005 mg/kg IV) + Inj. midazolam (0.05 mg/kg) + Inj. fentanyl citrate $(2 \mu \mathrm{g} / \mathrm{kg}$ IV) + Inj. xylocard (1-1.5 mg/kg) was given along with preoxygenation for 3 minutes before inducing anesthesia. Hemodynamic parameters (HR, SBP, DBP, and MAP) were recorded again just before induction.

Induction of anesthesia was done using Inj. propofol (2 $\mathrm{mg} / \mathrm{kg})$, followed by Inj. rocuronium $(0.9 \mathrm{mg} / \mathrm{kg} \mathrm{IV})$. Parameters (HR, SBP, DBP, and MAP) were recorded just after induction. Intubation was done after 90 seconds of rocuronium injection with endotracheal tube $(8.0 \mathrm{~mm}$ ID in males and $7.5 \mathrm{~mm}$ ID in females) either by Airtraq laryngoscope or by McCoy laryngoscope, depending on randomization. Position of the tube was checked by auscultation and confirmed by end tidal carbon dioxide $\left(\mathrm{EtCO}_{2}\right)$ tracings. Parameters (HR, SBP, DBP, and MAP) were recorded again, just after intubation and then 1,3 , and 5 minutes after intubation.

In each case, intubation time was noted, which was defined as the time taken from removal of face mask for intubation to removal of the laryngoscope and connection of anesthesia circuit to the endotracheal tube. Intubation was said to have failed if the introduction of the intubating device was not possible, or more than three attempts were required, or intubation time was more than 120 seconds. Modified intubation difficulty score (IDS) described by Adnet et al, using the seven parameters (number of operators, number of attempts, number of additional techniques, CormackLehane view, lifting force, laryngeal pressure, and vocal cord position) for intubation with Airtraq and McCoy laryngoscope was noted (- Table 1). ${ }^{12}$ Difficulty in insertion of laryngoscope was graded by the intubating anesthesiologist as per 
Likert's scale i.e., 2 (very difficult to insert) to +2 (very easy to insert). Airway-related complications in the form of injury to lips, teeth, mucosal injury, laryngospasm, bronchospasm, postoperative stridor, and sore throat were also noted.

Statistical analysis was performed by using SPSS Statistics version 22.0.0 (SPSS Inc., Chicago, Illinois, United States). Categorical variables (gender, ASA grade, and Mallampati grade) were presented as frequency, percentage and proportions and intergroup comparison of these variables was done using Chi-square test. Continuous variables, such as age, weight, airway parameters, duration of intubation, and hemodynamic parameters (HR, SBP, DBP, and MAP) were presented as mean \pm standard deviation. Intergroup comparison

Table 1 Modified intubation difficulty score (IDS)

\begin{tabular}{|c|c|c|}
\hline & McCoy laryngoscope & Airtraq \\
\hline N1 & $\begin{array}{l}\text { No. of intubation } \\
\text { attempts }>1\end{array}$ & $\begin{array}{l}\text { No. of intubation } \\
\text { attempts }>1\end{array}$ \\
\hline N2 & $\begin{array}{l}\text { The number of } \\
\text { operators }>1\end{array}$ & $\begin{array}{l}\text { The number of } \\
\text { operators }>1\end{array}$ \\
\hline N3 & $\begin{array}{l}\text { No. of alternative intu- } \\
\text { bation techniques used } \\
\text { Hinge used: } 1 \text {; Bougie } \\
\text { used: } 2 \text {; others (Magill } \\
\text { forceps, etc.): } 3\end{array}$ & $\begin{array}{l}\text { No. of alternative intuba- } \\
\text { tion techniques used } \\
\text { Bougie used: } 1 \text {; others } \\
\text { (Magill forceps, etc.): } 2\end{array}$ \\
\hline N4 & $\begin{array}{l}\text { Glottic exposure } \\
\text { (Cormack-Lehane: } \\
\text { grade:-1, N4 = 0) }\end{array}$ & $\begin{array}{l}\text { Glottic exposure } \\
\text { (Cormack-Lehane: } \\
\text { grade-1, N4 = 0) }\end{array}$ \\
\hline N5 & $\begin{array}{l}\text { Lifting force required } \\
\text { during laryngoscopy } \\
\text { normal: } 0 \text {; increased: } 1\end{array}$ & $\begin{array}{l}\text { Lifting force required } \\
\text { during laryngoscopy } \\
\text { normal: } 0 \text {; increased or } \\
\text { change in position of } \\
\text { Airtraq required: } 1\end{array}$ \\
\hline N6 & $\begin{array}{l}\text { Necessity for external } \\
\text { laryngeal pressure } \\
\text { no: } 0 \text {; yes: } 1\end{array}$ & $\begin{array}{l}\text { Necessity for external } \\
\text { laryngeal pressure } \\
\text { no: } 0 \text {; yes: } 1\end{array}$ \\
\hline N7 & $\begin{array}{l}\text { Position of the vocal } \\
\text { cords at intubation } \\
\text { abduction/not } \\
\text { visualized: } 0 ; \\
\text { adduction: } 1\end{array}$ & $\begin{array}{l}\text { Position of the vocal cords } \\
\text { at intubation } \\
\text { abduction/not visualized: } \\
0 \text {; adduction: } 1\end{array}$ \\
\hline
\end{tabular}

Abbreviation: IDS, intubation difficulty score. of continuous variables was done by unpaired $t$-test. Statistically significant level for the analyses was set as $p<0.05$.

\section{Results}

A total of 60 patients were enrolled in the study with 30 patients in each group. The demographic data and baseline airway characteristics amongst both the groups are summarized in - Table 2 . Both the groups were comparable with regard to age, weight, gender distribution, ASA grade distribution, Mallampati grade distribution, and distribution of airway parameters (thyromental distance, sternomental distance, mentohyoid distance, and neck circumference; - Table 2).

The mean time for intubation was $25.2 \pm 5.11$ seconds in Group A (Airtraq) and $27.3 \pm 4.47$ seconds in Group B (McCoy) and the difference was not statistically significant ( $p=0.14$; - Fig. 1). The mean intubation difficulty score was significantly lower in Group A (Airtraq) when compared with that in Group B (McCoy, $p=0.001$; - Table 3). There was statistically significant difference in the difficulty in insertion of laryngoscope between two groups suggesting that McCoy laryngoscope was difficult to insert as compared with Airtraq laryngoscope ( $p=0.04$; - Table 4 ).

The mean baseline hemodynamic variables (HR, SBP, DBP and MAP) were comparable in both the groups. In intergroup

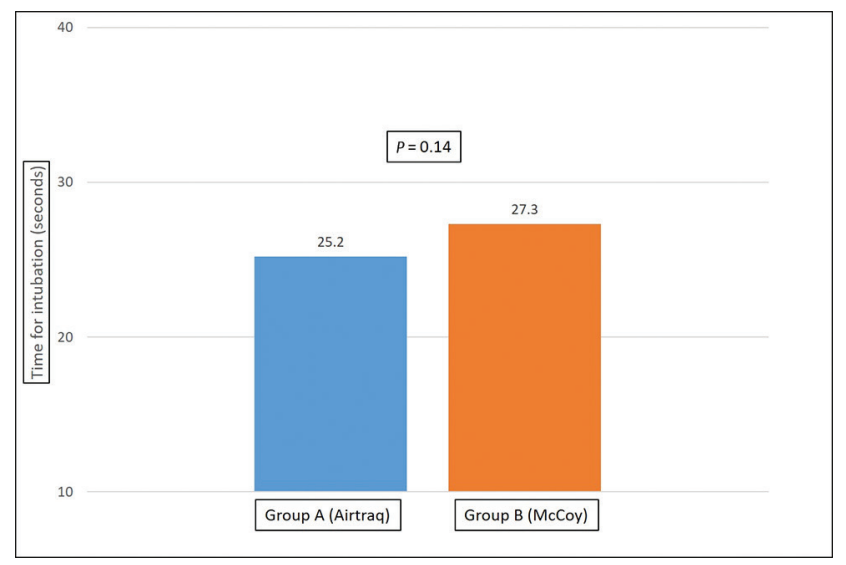

Fig. 1 Comparison of time taken for intubation (in seconds) between Airtraq and McCoy laryngoscopy.

Table 2 Demographic data and airway characteristics of the patients

\begin{tabular}{|l|l|l|l|}
\hline Characteristic & Group A (Airtraq) & Group B (McCoy) & $p$-Value \\
\hline Age $(Y)$ & $41.23 \pm 13.22$ & $38.27 \pm 7.362$ & 0.287 \\
\hline Sex (male/female) & $16 / 14$ & $18 / 12$ & 0.609 \\
\hline Weight $(\mathrm{kg})$ & $62.5 \pm 8.35$ & $63.53 \pm 7.86$ & 0.623 \\
\hline ASA grade $(1 / 2)$ & $18 / 12$ & $16 / 14$ & 0.609 \\
\hline Mallampati grade $(1 / 2 / 3)$ & $17 / 10 / 3$ & $19 / 8 / 3$ & 0.706 \\
\hline Thyromental distance $(\mathrm{cm})$ & $7.6 \pm 0.77$ & $7.85 \pm 0.69$ & 0.185 \\
\hline Mentohyoid distance $(\mathrm{cm})$ & $4.92 \pm 0.63$ & $17.34 \pm 2.80$ & 0.122 \\
\hline Sternomental distance $(\mathrm{cm})$ & $17.06 \pm 0.89$ & $35.16 \pm 2.81$ & 0.613 \\
\hline Neck circumference $(\mathrm{cm})$ & $34.30 \pm 2.06$ & $4.41 \pm 0.366$ & 0.183 \\
\hline Inter incisors gap $(\mathrm{cm})$ & $4.4 \pm 0.38$ & 0.917 \\
\hline
\end{tabular}


Table 3 Comparison of intubation difficulty score between Group A (Airtraq) and Group B (McCoy)

\begin{tabular}{|l|l|l|l|l|l|l|l|}
\hline Parameters & \multicolumn{3}{|c|}{ Group A (Airtraq) } & \multicolumn{3}{|c|}{ Group B (McCoy) } & \\
\hline IDS & Mean & SD & No. of patients & Mean & SD & No. of patients & $p$-Value \\
\hline N1 & 0 & 0 & 0 & 0.1 & 0.3 & 3 & 0.019 \\
\hline N2 & 0 & 0 & 0 & 0 & 0 & 0 & 1 \\
\hline N3 & 0 & 0 & 0 & 0.1 & 0.3 & 3 & 0.019 \\
\hline N4 & 0 & 0 & 0 & 0.17 & 0.37 & 6 & 0.009 \\
\hline N5 & 0.06 & 0.25 & 2 & 0 & 0 & 0 & 0.15 \\
\hline N6 & 0.03 & 0.18 & 1 & 0.2 & 0.43 & 6 & 0.02 \\
\hline N7 & 0 & 0 & 0 & 0 & 0 & 0 & 1 \\
\hline Total & 0.1 & 0.30 & & 0.53 & 0.62 & & 0.001 \\
\hline
\end{tabular}

Abbreviations: IDS, intubation difficulty score; SD, standard deviation.

Table 4 Comparison of difficulty in insertion of laryngoscope between Group A (Airtraq) and Group B (McCoy)

\begin{tabular}{|c|c|c|c|}
\hline Variables & Group A (Airtraq) & Group B (McCoy) & $p$-Value \\
\hline Very difficult $(-2)$ & 1 & 0 & \multirow[t]{5}{*}{0.004} \\
\hline Slightly difficult $(-1)$ & 3 & 9 & \\
\hline Not difficult (0) & 2 & 10 & \\
\hline Easy $(+1)$ & 19 & 10 & \\
\hline Very easy (+2) & 4 & 1 & \\
\hline
\end{tabular}

comparison, the increase in mean heart rate (just after intubation and 1 minute after intubation) in Group B (McCoy) was statistically significant as compared with that in Group A (Airtraq; $p=0.03,0.02$, respectively). After induction, mean SBP decreased in both the groups, but it increased to above postinduction values after intubation. The increase in SBP just after intubation and at 1-minute time point in Group B (McCoy) was statistically significant in contrast to that in Group A (Airtraq; $p=0.01,0.002$, respectively). Similarly, the mean DBP decreased in both the groups after induction, but it increased after intubation and remained above postinduction values at all time points. There was statistically significant difference in increase in DBP in Group B (McCoy) as compared with that in Group A (Airtraq) just after intubation and 1 minute after intubation time point $(p=0.02,0.04$, respectively). In both the groups, average MAP decreased after induction, which then increased after intubation and remained above the baseline values. The difference between the increase in MAP in Group B (McCoy) was statistically significant as compared with that in Group A (Airtraq) just after intubation and at 1-minute time point after intubation $(p=0.02,0.03$, respectively). This is illustrated in $\mathbf{- F i g .} \mathbf{2}$.

There was no difference in the incidence of complications in the two groups (- Table 5).

\section{Discussion}

Management of the airway is an important skill and responsibility for anesthesiologists. Failure of securing and managing an airway can lead to disastrous outcomes.

Effective management of an airway in cases of cervical spine injury is one of the major challenges faced by anesthesiologists. It necessitates cautious patient positioning, ${ }^{13}$ difficult intubation cart, presence of a skilled anesthesiologist, and a trained assistant for providing cervical spine immobilization. In patients with instability of cervical spine, immobilization of spine is necessary. Injury to the spinal cord has been reported during endotracheal intubation of such patients where immobilization of cervical spine is not implemented. ${ }^{11}$ Immobilization of spine results in difficulty in intubation. Use of cervical collar in situ or maneuver such as manual in line stabilization (MILS) for immobilization of cervical spine has been shown to reduce the necessary glottis exposure. ${ }^{14}$ Reduced inter incisor gap and immobility of cervical spine contributes to a large number of cases with grades 3 and 4 laryngoscopic views during conventional laryngoscopy with the use of a rigid cervical collar, tape, and sandbags. ${ }^{15}$

Several devices have been developed to overcome these issues, particularly in patients at risk of cervical spine injury. A variety of work has been done to study the laryngoscopic view, ease of intubation, hemodynamic changes during laryngoscopy, and intubation and associated complications in patients with cervical collar in situ. ${ }^{12}$

The Airtraq video-laryngoscope has been designed to facilitate intubation in normal and anticipated difficult cases. It does so, because of its blade with exaggerated curvature and an internal arrangement of optical components which facilitates a better view of the glottis and reduces the number of airway optimization maneuvers required. In patients with immobilized cervical spine, Airtraq has been shown to have advantages over direct laryngoscopy, which is difficult or not recommended. ${ }^{16-18}$ Advantages of Airtraq over McCoy laryngoscope mentioned in literature include less time for intubation, better intubation difficulty score, limited 

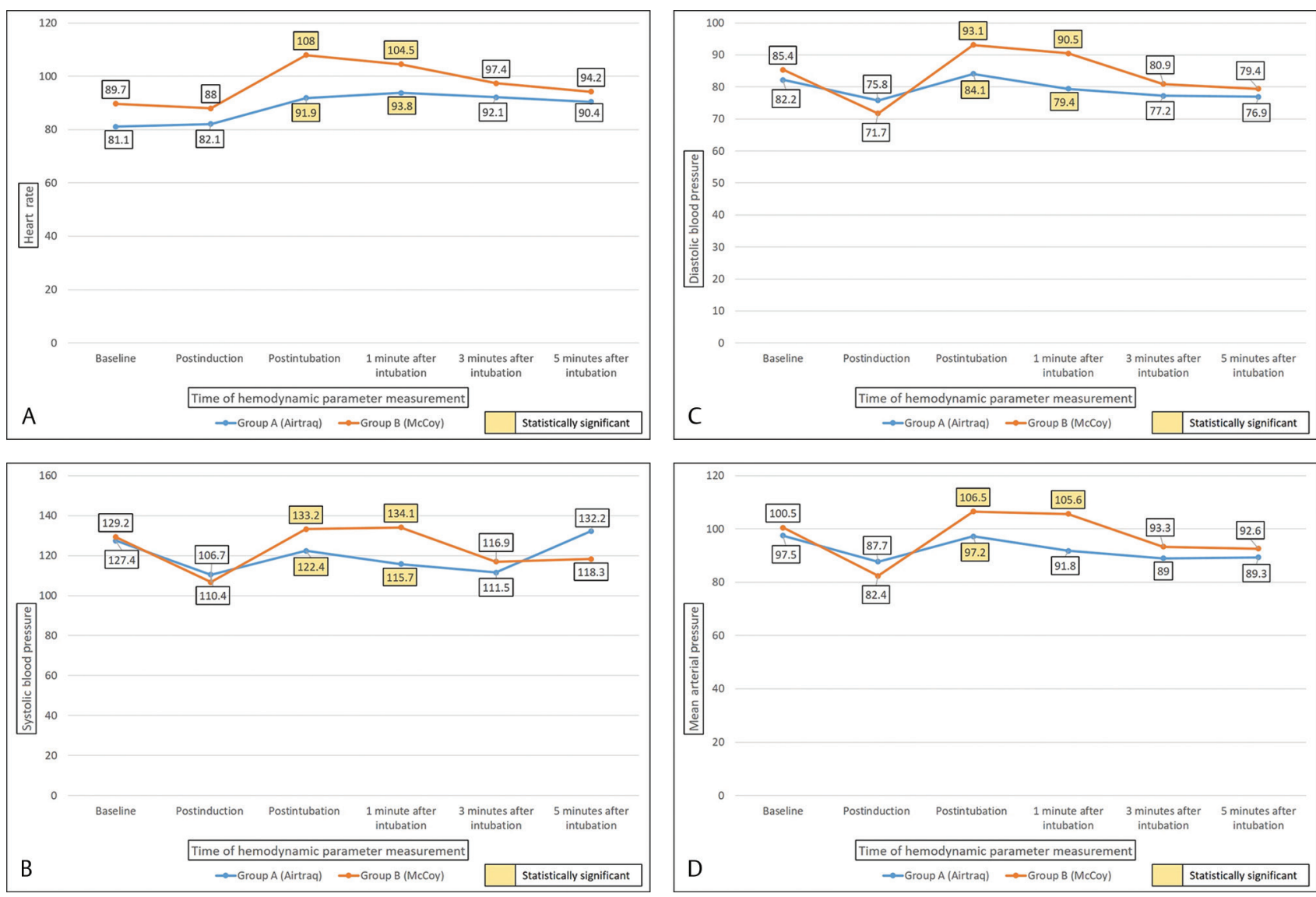

Fig. 2 (A-D) Comparison of changes in hemodynamic parameters at different time points before and after intubation with Airtraq and McCoy laryngoscope.

Table 5 Comparison of airway complications amongst the two groups

\begin{tabular}{|l|l|l|l|}
\hline Variables & Group A (Airtraq) & Group B (McCoy) & p-Value \\
\hline Lip injury & $1(0.03 \%)$ & $1(0.03 \%)$ & 0.82 \\
\cline { 1 - 3 } Sore throat & $2(0.06 \%)$ & $3(0.1 \%)$ & \\
\cline { 1 - 3 } Nil & $27(99 \%)$ & $26(98.7 \%)$ & \\
\hline
\end{tabular}

movements at the cervical spine, and ease of intubation in patients with normal airways. ${ }^{11,19}$

Our study aimed to evaluate the relative efficacy of Airtraq laryngoscope and McCoy laryngoscope when used by an experienced anesthesiologist in the clinical setting of simulation of cervical immobilization using rigid cervical collar, in terms of time taken for intubation as the primary outcome of the study. Shorter the time taken for intubation less would be the hypoxia and its deleterious effects on body's hemodynamics.

Turkstra et al reported 66\% lesser movement at occiputC1, C2 to C5 and C5 to thoracic segments with Airtraq than that during Macintosh laryngoscopy. ${ }^{19}$ Also, higher success rate of intubation have been reported with Airtraq in patients with cervical immobilization with collar by Koh et al. ${ }^{20} \mathrm{Arslan}$ et al evaluated the effectiveness of the Airtraq as compared with LMA CTrach devise in patients with simulated cervical spine injury after application of a rigid cervical collar. They found that Airtraq shortened the tracheal intubation time and reduced the mucosal damage when compared with the CTrach. ${ }^{21}$

In contrast to the previous studies, the present study showed that there was no significant difference in the time taken for intubation with Airtraq as compared with McCoy laryngoscope. Though the time taken for intubation was less in Airtraq than McCoy, the difference was not statistically significant $(p=0.142)$. The time for intubation was slightly longer than usual, in both the groups, which could have been attributed by the presence of cervical collar. The time taken for intubation also depends on the skill of the anesthesiologist, thus explaining the variability in duration of intubation in various studies evaluating $\mathrm{McCoy}^{15,22,23}$ and Airtraq laryngoscope. Haidry et $\mathrm{al}^{24}$ found an intubation time of $22.8 \pm 4.1$ seconds with McCoy laryngoscope, Komatsu et al ${ }^{25}$ noted that the time taken for intubation with McCoy was 40 \pm 14 seconds and Joseph et a $^{26}$ observed intubation time of 22.9 seconds with McCoy. Maruyama et a ${ }^{27}$ found $23 \pm 5$ seconds as time taken for intubation with McCoy laryngoscope. 
Durga et al $^{11}$ reported $33.27 \pm 13.25$ seconds of time to intubation with McCoy and $28.95 \pm 18.53$ seconds with Airtraq and concluded that there was not any significant difference between the time taken for intubation between the two devices, which is in corroboration with our results. In contrast, study by Aliet al ${ }^{28}$ showed that the time taken for intubation was significantly less with Airtraq laryngoscope than the McCoy. In the present study, we demonstrated that the time taken for intubation is almost the same with Airtraq and McCoy laryngoscope suggesting that no device is superior to another in terms of preventing hypoxia in emergent situations.

Intubation difficulty score was found to be significantly lower in Group A (Airtraq) as compared with Group B (McCoy). Also, Group A (Airtraq) required lesser intubation attempts, no change of position, better Cormack-Lehane grading, no lifting force, and less external laryngeal pressure as compared with McCoy group which was statistically significant. Similar findings were noted by Durga et $\mathrm{al}^{11}$ who in their study concluded that intubation attempts, number of operators, alternative techniques for intubation, lifting force, and external laryngeal pressure required were higher in patients of McCoy group as compared with that of Airtraq group.

Difficulty in intubation despite good glottic visualization is a problem reported with most video laryngoscopes. ${ }^{29}$ Difficulty in insertion of laryngoscope is a parameter, we recorded as per Likert's scale i.e., -2 which was very difficult to insert Airtraq or McCoy laryngoscope to +2 which was very easy to insert. There was significant difficulty in inserting McCoy as compared with Airtraq.

Comparison of mean values of heart rate, SBP, DBP and MAP at different time points showed that these hemodynamic parameters were lower and more stable in Group A (Airtraq) than in Group B (McCoy) with significant differences at post intubation time point and 1 minute after intubation.

According to the study conducted by McCoy et al, ${ }^{30,31}$ use of McCoy laryngoscope reduces the force required for better laryngoscopy by lifting epiglottis and ultimately reducing stress response to laryngoscopy. Nishiyama et $\mathrm{al}^{29}$ and Tewari et al $^{32}$ compared McCoy and Macintosh blades and showed that use of McCoy blade resulted in lesser change in HR and BP. On the other side, some studies (Han et al, ${ }^{33}$ Román et $\mathrm{al}^{34}$ and Shimoda et $\mathrm{al}^{35}$ ) did not find any significant difference in the circulatory response between McCoy blade and Macintosh blade. This finding could be attributed to the fact that the Airtraq provides a view of the glottis without aligning the oral, pharyngeal, and tracheal axes and therefore requires less force to be applied during laryngoscopy, while using a cervical collar in situ which did not allow alignment of the three airway axes and lead to more lifting force and more manipulations with McCoy laryngoscope, to get a glottic view.

No major complication was noted in any of the group, except lip injury and sore throat, which were statistically not significant. However, Durga et al $^{11}$ demonstrated significantly less airway trauma with Airtraq compared with McCoy laryngoscope.
Our study has few limitations. First, blinding of the anesthesiologist to the device being used was not possible, leading to a potential bias. Second, some of the measurements in the study are subjective. Another limitation is that the intubation was performed by an experienced anesthesiologist and hence the results seen may differ in the hands of less experienced anesthesiologists.

\section{Conclusion}

We conclude that although, with Airtraq laryngoscope, intubation can be performed more swiftly in emergency situations requiring cervical immobilization, which is of utmost priority to avoid further neurological injury, the time taken for intubation is similar to that of McCoy. This suggests that there is no device which can be labeled as superior over another in terms of preventing hypoxia.

\section{Conflict of Interest}

None declared.

\section{References}

1 Goldberg W, Mueller C, Panacek E, Tigges S, Hoffman JR, Mower WR; NEXUS Group. Distribution and patterns of blunt traumatic cervical spine injury. Ann Emerg Med 2001;38(1):17-21

2 Dunham CM, Barraco RD, Clark DE, et al. EAST Practice Management Guidelines Work Group. Guidelines for emergency tracheal intubation immediately after traumatic injury. J Trauma 2003;55(1):162-179

3 Stein DM, Menaker J, McQuillan K, Handley C, Aarabi B, Scalea TM. Risk factors for organ dysfunction and failure in patients with acute traumatic cervical spinal cord injury. Neurocrit Care 2010;13(1):29-39

4 Hastings RH, Kelley SD. Neurologic deterioration associated with airway management in a cervical spine-injured patient. Anesthesiology 1993;78(3):580-583

5 Goutcher CM, Lochhead V. Reduction in mouth opening with semi-rigid cervical collars. Br J Anaesth 2005;95(3):344-348

6 Wakeling HG, Nightingale J. The intubating laryngeal mask airway does not facilitate tracheal intubation in the presence of a neck collar in simulated trauma. $\mathrm{Br} \mathrm{J}$ Anaesth 2000;84(2):254-256

7 Heath KJ. The effect of laryngoscopy of different cervical spine immobilisation techniques. Anaesthesia 1994;49(10):843-845

8 Gercek E, Wahlen BM, Rommens PM. In vivo ultrasound realtime motion of the cervical spine during intubation under manual in-line stabilization: a comparison of intubation methods. Eur J Anaesthesiol 2008;25(1):29-36

9 Prasarn ML, Conrad B, Rubery PT, et al. Comparison of 4 airway devices on cervical spine alignment in a cadaver model with global ligamentous instability at C5-C6. Spine 2012;37(6):476-481

10 Fuchs G, Schwarz G, Baumgartner A, Kaltenböck F, Voit-Augustin H, Planinz W. Fiberoptic intubation in 327 neurosurgical patients with lesions of the cervical spine. J Neurosurg Anesthesiol 1999;11(1):11-16

11 Durga P, Kaur J, Ahmed SY, Kaniti G, Ramachandran G. Comparison of tracheal intubation using the Airtraq( $\left({ }^{\circledR}\right)$ and Mc Coy laryngoscope in the presence of rigid cervical collar simulating cervical immobilisation for traumatic cervical spine injury. Indian J Anaesth 2012;56(6):529-534

12 Sarvaiya N, Thakur DP, Tendolkar BA. A comparative study of endotracheal intubation as per intubation difficulty score, using Airtraq and McCoy laryngoscopes with manual-in-line 
axial stabilization of cervical spine in adult patients. Int J Res Med Sci 2016;4(8):3211-3218

13 Umamaheswara Rao GS. Anaesthetic and intensive care management of traumatic cervical spine injury. Indian J Anaesth 2008;52:13

14 Smith CE, Pinchak AB, Sidhu TS, Radesic BP, Pinchak AC, Hagen JF. Evaluation of tracheal intubation difficulty in patients with cervical spine immobilization: fiberoptic (WuScope) versus conventional laryngoscopy. Anesthesiology 1999;91(5):1253-1259

15 Forbes AM, Dally FG. Acute hypertension during induction of anaesthesia and endotracheal intubation in normotensive man. Br J Anaesth 1970;42(7):618-624

16 Maharaj CH, Higgins BD, Harte BH, Laffey JG. Evaluation of intubation using the Airtraq or Macintosh laryngoscope by anaesthetists in easy and simulated difficult laryngoscopy-a manikin study. Anaesthesia 2006;61(5):469-477

17 Maharaj CH, Costello JF, Harte BH, Laffey JG. Evaluation of the Airtraq and Macintosh laryngoscopes in patients at increased risk for difficult tracheal intubation. Anaesthesia 2008;63(2):182-188

18 Maharaj CH, O'Croinin D, Curley G, Harte BH, Laffey JG. A comparison of tracheal intubation using the Airtraq or the Macintosh laryngoscope in routine airway management: A randomised, controlled clinical trial. Anaesthesia 2006;61(11):1093-1099

19 Turkstra TP, Pelz DM, Jones PM. Cervical spine motion: a fluoroscopic comparison of the AirTraq Laryngoscope versus the Macintosh laryngoscope. Anesthesiology 2009;111(1):97-101

20 Koh JC, Lee JS, Lee YW, Chang CH. Comparison of the laryngeal view during intubation using Airtraq and Macintosh laryngoscopes in patients with cervical spine immobilization and mouth opening limitation. Korean J Anesthesiol 2010;59(5):314-318

21 Arslan ZI, Yildiz T, Baykara ZN, Solak M, Toker K. Tracheal intubation in patients with rigid collar immobilisation of the cervical spine: a comparison of Airtraq and LMA CTrach devices. Anaesthesia 2009;64(12):1332-1336

22 Practice guidelines for management of the difficult airway. A report by the American Society of Anesthesiologists Task Force on management of the difficult airway. Anesthesiology 1993;78(3):597-602

23 Murphy P. A fibre-optic endoscope used for nasal intubation. Anaesthesia 1967;22(3):489-491
24 Haidry MA, Khan FA. Comparison of hemodynamic response to tracheal intubation with Macintosh and McCoy laryngoscopes. J Anaesthesiol Clin Pharmacol 2013;29(2):196-199

25 Komatsu R, Kamata K, Sessler DI, Ozaki M. A comparison of the Airway Scope and McCoy laryngoscope in patients with simulated restricted neck mobility. Anaesthesia 2010;65(6):564-568

26 Joseph J, Sequeira T, Upadya M. Comparison of the use of McCoy and TruView EVO2 laryngoscopes in patients with cervical spine immobilization. Saudi J Anaesth 2012;6(3):248-253

27 Maruyama K, Yamada T, Kawakami R, Kamata T, Yokochi M, Hara K. Upper cervical spine movement during intubation: fluoroscopic comparison of the AirWay Scope, McCoy laryngoscope, and Macintosh laryngoscope. $\mathrm{Br} \mathrm{J}$ Anaesth 2008;100(1):120-124

28 Ali QE, Das B, Amir SH, Siddiqui OA, Jamil S. Comparison of the Airtraq and McCoy laryngoscopes using a rigid neck collar in patients with simulated difficult laryngoscopy. J Clin Anesth 2014;26(3):199-203

29 Nishiyama T, Higashizawa T, Bito H, Konishi A, Sakai T. [Which laryngoscope is the most stressful in laryngoscopy; Macintosh, Miller, or McCoy?]. Masui 1997;46(11):1519-1524

30 McCoy EP, Mirakhur RK. The levering laryngoscope. Anaesthesia 1993;48(6):516-519

31 Farling PA. The McCoy levering laryngoscope blade. Anaesthesia 1994;49(4):358

32 Tewari P, Gupta D, Kumar A, Singh U. Opioid sparing during endotracheal intubation using McCoy laryngoscope in neurosurgical patients: the comparison of haemodynamic changes with Macintosh blade in a randomized trial. J. Postgrad Med 2005;51(4):260-264

33 Han TS, Kin JA, Park NG, Lee SM, Cho HS, Chung IS. A comparison of the effects of different types of laryngoscope on haemodynamics: McCoy versus the Macintosh blade. Korean J Anesthesiol 1999;37(3):398-401

34 Román J, Beltrán de Heredia B, García-Velasco P, et al. Hemodynamic response to intubation with Macintosh and McCoy blades [article in Spanish]. Rev Esp Anestesiol Reanim 1996;43(5):177-179

35 Shimoda O, Ikuta Y, Isayama S, Sakamoto M, Terasaki H. Skin vasomotor reflex induced by laryngoscopy: comparison of the McCoy and Macintosh blades. Br J Anaesth 1997;79(6):714-718 